\title{
Best overall dimensions of synchronous generator with permanent magnets for small power wind plants and micro hydropower plants
}

\author{
Nurali Pirmatov ${ }^{1, *}$, Shaxnoza Tosheva ${ }^{1}$, and Sherzod Toshev ${ }^{2}$ \\ ${ }^{1}$ Tashkent State Technical University named after I. Karimova, 100095, Tashkent, Uzbekistan \\ ${ }^{2}$ Joint stock company Uzbekgidroenergokurulish, 100077, Tashkent, Uzbekistan
}

\begin{abstract}
The overall dimensions of a synchronous generator with permanent magnets are determined by its main dimensions - the length $l_{p}$ and active part of the rotor with a diameter $D_{p}$, so the larger the air gap, the smaller the magnetic induction in it and vice versa. The force of gravity, in turn, will also depend on the air gap. The structurally incorporated unevenness of the air gap leads to an increase in the attractive force in the place of the smallest gap value, which leads to the appearance of a bending moment. As a result, the disc skews and the load on the bearings increases
\end{abstract}

\section{Introduction}

Renewable energy is the energy received as a result of natural processes, which are replenished faster than they are consumed. Common sources of renewable energy include solar, wind, geothermal and some types of biomass.

More than $80 \%$ of global energy consumption is fossil resources, which are depleted faster than they can be recovered. Due to growing concerns about carbon emissions and uncertainty in fossil fuel supplies, interest in clean and renewable energy is constantly growing [1].

\section{Discussion}

The generator is the most important element of the electrical equipment of the wind turbine and microhydroelectric power plant. The advantages of generators with permanent magnets include high reliability, ease of construction and maintenance associated with the absence of sliding contacts and rotating winding, autonomy since no constant current is required for excitation, less heating due to the absence of excitation losses [2].

In a low-speed synchronous generator, electromagnetic processes occur that affect the performance of the structure.

The setting parameter of the electromagnetic processes of the generator is magnetic induction, knowing which, you can find the force with which the rotor is attracted to the stator, and an important argument will be the size of the working air gap. The larger the air gap, the smaller the magnetic induction in it and vice-versa. The force of gravity, in turn, will also depend on the air gap. Structurally, the unevenness of the air gap leads to an increase in the attractive force at the place of the smallest value of the gap, which leads to the appearance of a bending moment. As a result, there is a skew of disks and the load on bearings increases [3].

A generator with a permanent magnet rotor can be built according to various schemes, differing from each other by the joint arrangement of windings and magnets. Alternating polarity magnets are located on the rotor of the generator. Windings with alternating winding direction are located on the generator stator. If the rotor and stator are coaxial disks, then this type of generator is called axial or disk.

The overall dimensions of the SGPM are determined by its main dimensions - the length $l_{p}[\mathrm{~mm}]$ and the active part of the rotor with a diameter $D_{p}[\mathrm{~mm}][4,5]$ :

$$
\begin{aligned}
& D_{p}^{2} \cdot l_{p}=\frac{C_{A} \cdot P_{\mathrm{est}}}{n} \\
& C_{A}=\frac{6,1 \cdot 10^{7}}{\alpha_{i} \cdot k_{\Phi} \cdot k_{O} \cdot A \cdot B_{\delta}}
\end{aligned}
$$

where $P_{\text {est }}$ - estimated power of SGPM, [W];

$C_{A}$ - Arnold's machine constant;

$\alpha_{i}$ - estimated coefficient of pole overlap;

$k_{\phi}$ - coefficient of the shape of the curve of the field;

$k_{O}$ - winding coefficient;

$A$ - linear load, [A / cm];

$B_{\delta}$ - the maximum value of induction in the air gap at rated load $[\mathrm{T}]$;

$n$ - rotor speed [r/ $\mathrm{min}]$;

The estimated power is determined by the formula:

\footnotetext{
* Corresponding author: tshe100679@gmail.com
} 


$$
P_{\text {est }}=\frac{\kappa_{e} \cdot P_{H}}{\cos \varphi}
$$

Where $k_{e}=\frac{E_{i}}{U_{H}}$ - coefficient characterizing the EMF of the anchor winding.

SGPMs are characterized by the highest energy efficiency, they are characterized by the minimum possible internal losses.

$$
\Delta P=\Delta P_{\text {copper }}+\Delta P_{\text {steel }}+\Delta P_{\text {extra }}
$$

\section{Comparative results}

It should be noted that the ratio of power losses in highfrequency and low-frequency SGPMs differ from each other. In classic low-frequency machines, the main share is electric (in copper) and magnetic (in steel) losses and additional losses associated with rotor friction against air and losses in bearings account for only $5-10 \%$ of the total power loss $[4,6,7]$.

On the contrary, in high-frequency EM, the proportion of additional losses increases significantly. In particular, low-speed high-torque synchronous generators with a fixed armature and rotating magnets and with additional transverse windings can be used as wind generators, high-frequency electric generators and in stand-alone power plants $[5,8,9,10]$.

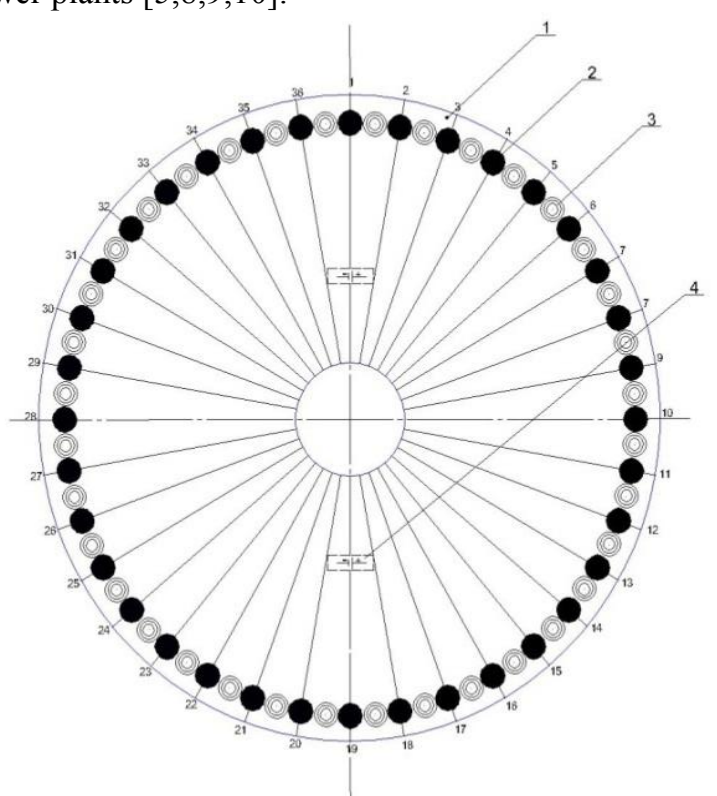

Fig. 1. Rotor: 1- rotor disk, 2-permanent magnet, 3-additional transverse windings, 4-battery

A low-speed permanent magnet electric generator contains a rotor (Fig. 1.) in the form of two flat disks, a stator (Fig. 2.) is placed between the rotor disks and is made in the form of a disk connected to a fixed case, the anchor winding is located on the disk along the radii reel magnets with alternating poles and additional transverse windings mounted on the side parts of the rotor in an amount of 36 to 360 on each disk.

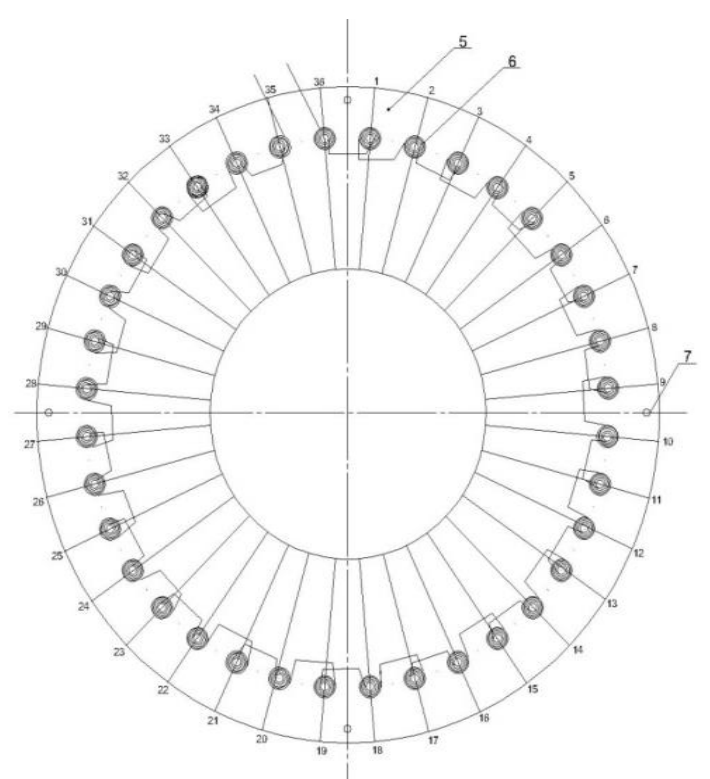

Fig. 2. Stator: 5-stator disk, 6-stator winding, 7- places for fixing

The implementation of 36 to 360 alternating permanent magnets on each rotor disk and the installation of an additional transverse winding ensures the efficiency of the proposed low-speed permanent magnet electric generator Fig. 3.

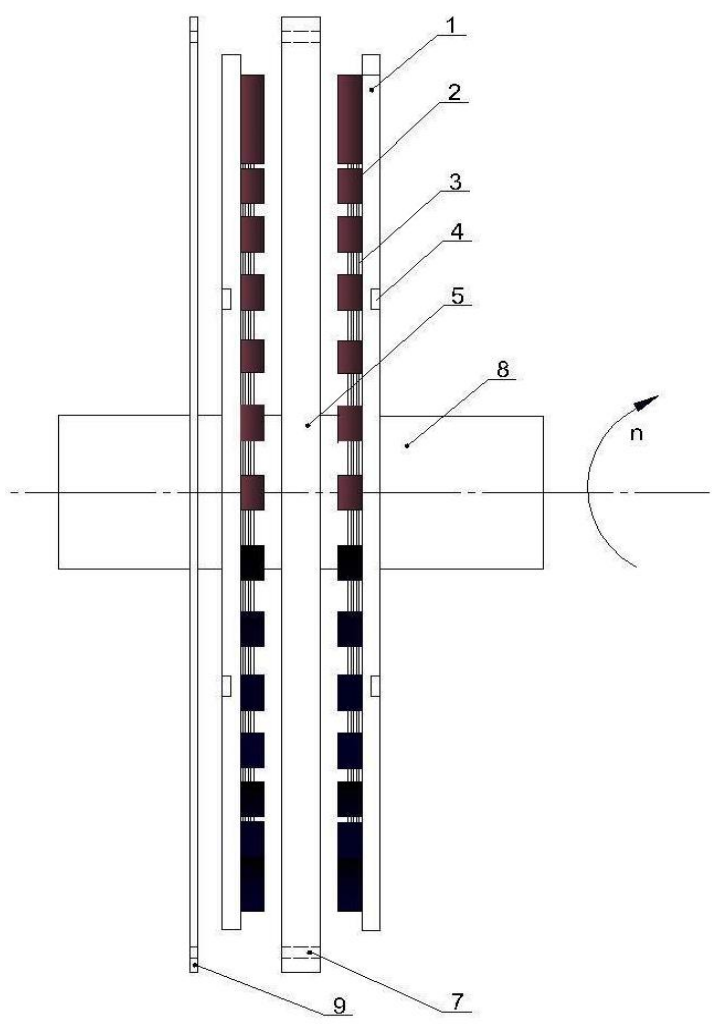

Fig. 3. General view of the generator: 8-shaft, 9-body

In the known electric generator, the number of constantly alternating magnets is in the range from 40 to 120 , while the possibility of rotation of the rotor is from 50 to $60 \mathrm{rpm}$, which does not allow the use of this electric generator in various farms, agricultural 
enterprises on ravine rivers with a low flow rate, while to ensure the rotation of the rotor 50-60 rpm, a step-up reducer is required, which complicates and increases the cost of the electric generator. Power supply to consumers due to the distance from the power system and low power requires high costs. The great length and branching of power lines, wear and tear of electric networks cause significant losses of electricity. As a result, there is an increase in electricity costs, which generally reduces the efficiency of production at enterprises and worsens the conditions of comfortable living of the population. In the further development strategy of the Republic of Uzbekistan for the years 2017-2021 was determined "...to reduce energy intensity and resource intensity of the economy, wide introduction in manufacture of energy-saving technologies, increased use of renewable sources of energy, increasing productivity in sectors of the economy...".

The task, which is aimed at solving, is to increase the efficiency of the generator. The technical result is an increase in power, an increase in EMF, a decrease in rpm and rated speed, as well as a decrease in electromagnetic torque.

\section{Conclusion}

The proposals presented in this paper open up the prospect of further research on the extremely important problem of estimating the power loss in high-frequency and low-frequency SGPMs. In classical low-frequency machines, the main share is electric (in copper) and magnetic (in steel) losses, and additional losses associated with rotor friction against air and losses in bearings account for only $5-10 \%$ of the total power loss.

\section{References}

1. A.Mohamed. Ph.D Disser., 175 (2014)

2. Krivtsov, V.S., Oleinikov, A.M., Yakovlev, A.I. Inexhaustible Energy, Pr. Textbook. 400 (2003)

3. Balagurov V.A. Design of special AC electric machines. - M .: Higher. School, 272 (1982)

4. Balagurov V.A., Galteev F.F. Permanent magnet electric generators. - M.: Energoatomizdat, 280 (1988)

5. Pirmatov N.B., Toshev Sh.E., Tosheva Sh.N., Egamov A. Low-speed generator of a new type used to generate electric energy based on renewable energy sources. // International scientific conference. 123-124 (2018)

6. K.S. Fediy, A.L. Vstovsky. Optimization of the operating modes of electrical systems. Interuniversity collection of scientific papers. Krasnoyarsk CPC KSTU. 56-61 (2006)

7. Booth D.A. Contactless electric machines: textbook. YES. Booth M .: Higher school, 416(1990)

8. Pirmatov N.B., Toshev Sh.E., Haydarov S.D., Tosheva Sh.N. European Conference on Innovations in Technical and Natural Sciences.:, $15^{\text {th }}$ International scien. Conf.. 105-110 (2017)

9. Toshev Sh.E., Pirmatov N.B., Haydarov S.D., Duvlonov J.N., Yakubova D.K. Europ. Scien. R.:Aust, Vienna,11-12, 134-136 (2016)

10. Akhmatov M. G. Synchronous machines. Special course. - Moscow: higher school, 136 (1984) 